\title{
(Why) do selfish people self-select in economics?
}

\author{
ALESSANDRO LANTERI \\ University of Piemonte Orientale
}

\begin{abstract}
Several game-theoretical lab experiments helped establish the belief that economists are more selfish than non-economists. Since differences in behaviour between experiment participants who are students of economics and those who are not may be observed among junior students as well, it is nowadays widely believed that the origin of the greater selfishness is not the training they undergo, but selfselection. In other words, selfish people voluntarily enrol in economics. Yet, I argue that such explanation is unsatisfactory for several reasons. I also suggest alternative explanations for the observed differences, which have been so far unduly disregarded.
\end{abstract}

Keywords: economics, experiments, moral trial, self-interest, selfselection

JEL Classification: A11, A13, A14, C70, C90

Do economists make bad citizens? (R. Frank, et al. 1996). Are political economists selfish and indoctrinated? (Frey and Meier 2003). How tempting is corruption? More bad news about economists (B. Frank and Schulze 1998). With so many obvious value judgments, these are questions one would not expect to read in an economics article and, with such a dismal depiction of their profession, one would expect economists to answer negatively. Both expectations would be wrong.

These unflattering questions are but a small sample of the titles of economics articles from a stream of literature that has waged against the economics profession a veritable 'moral trial' (Lanteri 2008a). Moreover, although some attempts have been made at defending economists (Yezer, et al. 1996; Laband and Beil 1999; Lanteri 2008a, 2008b; Hu and Liu 2003; Zsolnai 2003), affirmative answers to these questions prevail by far, both among economists and non-economists.

AUTHOR's NoTE: I am grateful to two anonymous referees, and to Tom Wells, for very useful comments. Remaining mistakes are my responsibility. 
To be under these types of attacks may not be altogether surprising for the practitioners of a discipline which, since its origin, has been criticized for countless reasons (Coleman 2004): because it is false, useless, or harmful, because its practice is conceited, biased, bidden, or methodologically inadequate, because its subject is overstretched in scope or overemphasized in value, and so forth. Such longstanding hostility is perhaps a reflection of economists having different opinions from the rest of the people, not only when it comes to strictly economic matters (McCloskey 1990; Caplan 2001; Rubin 2003; Klamer 2007), but also political (Kearl, et al. 1979; Fuller and Geide-Stevenson 2007) and moral ones (Frey, et al. 1993; Haucap and Just 2003).

Yet, where do these differences come from?

Quite simply, those who have faith in the overarching power of selfinterest may gravitate towards economics so that, as Steven Rhoads $(1985,162)$ wrote in The economist's view of the world, the "[p]eople who think [...] narrow self-interest makes sense are more likely to become economists". In other words, there is a process of self-selection into the discipline. On the other hand, training in economics may modify the view of the world of its students. Therefore, George Stigler $(1959,528)$ suggested that the origin of the differences "surely lies in the effect of scientific training the economist receives", because the typical economics student "is drilled in the problems of all economic systems and in the methods by which a price system solves these problems!"

The differences in economic, political, and moral opinions seem indeed to reflect the central features of economic theory, according to which individual agents behave as self-interested and rational 'economic men' and their voluntary interactions in free markets produce an optimal final state. Though this simplistic vision of the world is arguably no longer part of the mainstream, it is the kind of economic knowledge that is regularly fed to undergraduate students (Colander 2007).

Such an 'economist's worldview', moreover, may have consequences that reach farther than personal opinions. It has been shown in several lab experiments (Marwell and Ames 1981; Carter and Irons 1991; Frank, et al. 1993; Rubinstein 2006) that economics students behave in accordance with the predictions of economic theory-i.e., selfishlywhereas non-economics students behave contrary to those predictions. As a reaction to such evidence, it has become common to accept the claim that "economists are more selfish than other persons" as "a fact 
beyond doubt" (Frey and Meier 2002, 2). This literature, therefore, moves beyond the traditional critiques of the discipline of economics and focuses instead on the individual behaviour of economists in an attempt to uncover their morals.

On the whole, this literature can be regarded as a moral trial against economists on charges of selfishness. The trial is moral because of two unusual features of this literature compared with most economics articles: a clear focus on the personal character and behaviour of individual economists with respect to a normative moral standard; and the abundance of value judgments, which reflects a level of emotional involvement that surpasses the typical intellectual curiosity of a scientific inquiry. ${ }^{1}$ What makes the moral trial a trial, instead, are the prescriptions for correcting this deviant moral conduct.

Yet, corrections may only be advocated and enforced after some clarity has been shed on the origin of the misdeed. For instance, one could suggest that the content or the method of economics teaching should be changed, but this would only be effective if economics teaching had an effect on economists' selfish conduct. If one subscribes to the self-selection explanation, on the other hand, this is no longer the case. Self-selection may be a moral accusation, to be sure, but it is not one that economics teachers are accountable for. If selfish people converge to the discipline, what can economists do?

Within this moral trial, as I collectively refer to the contributions to the literature on the morality of economists, the training explanation for the origins of the difference in selfishness has received very little support and most researchers have found indications of self-selection, which is therefore accepted as the leading interpretation for the evidence.

In the following, however, I will address two orders of problems: whether we can conclude that economists are more selfish than noneconomists and, to the extent that this is the case, whether the difference is explained by self-selection. With regard to the first problem, I will argue that the experimental evidence is not strongly conclusive, so the difference between economists and non-economists is

\footnotetext{
1 One criterion to define a moral issue versus a non-moral one is emotional involvement. If we disagree about whether red wine goes with fish, the extent of our passion in defending our opinion against the opposing view is most likely milder than the passion involved in a disagreement over paedophilia. The latter is thus a moral issue, because it passes a critical threshold on an "emotional staircase" (Blackburn 1998, 9ff.). This seems the case of the moral trial as well; Ariel Rubinstein for example thanks the many economists who confirmed that his work "hit a nerve" (2006, c1n.).
} 
not as sharp as it is sometimes presented to be. With regard to selfselection, I will complain that it is poorly specified and that it does not truly amount to a satisfactory explanation. Moreover, other explanations for the observed differences in behaviour, which might deepen our understanding of the conduct of economics majors and non-majors, have been unduly disregarded.

\section{THE MORAL TRIAL}

It was in the early Eighties that the first lab experiments were published which pointed out a behavioural difference between economists and non-economists. In a study of the private provision of public goods, the psychologists Gerald Marwell and Ruth Ames (1981) endowed their subjects with some tokens. Each participant could put her tokens into either an individual investment (a private good) or a collective investment (a public good). For every token invested in the private good, each participant received a small amount of money. Each token invested in the public good was awarded a larger amount of money, which was pooled and then equally shared among all participants-including those who had not invested in the public good. Economic theory predicts that nobody voluntarily contributes to a public good-i.e., everybody free rides-in the hope that they may still reap the fruits of the collective investment, should other participants so allocate their tokens. This is regrettable because, thanks to the higher compensation, the social optimum obtains when every participant puts all her tokens in the public good. Marwell and Ames show that various samples of students put roughly $49 \%$ of their endowed tokens into the collective investment: behaviour that is far from being collectively optimal, but also far from the predictions of economic theory. On the other hand, graduate students of economics only invested $24 \%$ of their tokens in the public good: not the strong free-riding pattern that economists would predict, but much closer to that.

This line of inquiry was extended ten years later, when John Carter and Michael Irons (1991) conducted an ultimatum bargaining game among randomly recruited freshmen and senior students, majoring in either economics or non-economics (and none of whom had ever enrolled in or taken graduate economics courses). They, too, confirmed that "a behavioral difference [between economists and non-economists] does exist” (Carter and Irons 1991, 171). 
The ultimatum game consists of dividing a fixed amount of money among two players: a proposer, who makes the division, and a responder, who may accept or reject the division offered. If the responder accepts, the division takes place as proposed. If she rejects, both players earn zero. Economic theory would suggest that the proposer keep as much as possible for himself, say 99.99\%, and offer a mere $0.01 \%$ to the responder. The responder, on the other hand, should accept even that minuscule share, as it is better than nothing. Carter and Irons, therefore, asked the participants to state both the minimum amount they would find acceptable if it were offered to them by another player and the amount they would offer to another player. On average, non-economics students declared that they would accept $24.4 \%$ or more of the original sum and that they would keep 54.4\%. Economics students, on the other hand, would keep $61.5 \%$ of the initial endowment for themselves and would be happy to be offered a mere $17 \%$. Once again, the evidence reveals conduct that places economics students closer than the others to the standards set by economic man. The second important finding is that this difference can already be observed between freshmen, who had not had enough time to be indoctrinated by economics teachers. This is interpreted to mean that the phenomenon must be explained by self-selection. In short: "[e]conomists are born, not made" (Carter and Irons 1991, 174).

In another famous experiment, Robert Frank, Thomas Gilovich, and Dennis Regan (1993) assembled groups of three students. Each participant played two simultaneous prisoner's dilemmas with each of the other participants. In such situations, each individual faces a decision in which one choice (i.e., defection) yields a higher payoff (i.e., it is a dominant strategy), regardless of the choice made by the other player. If both players make that choice, however, each participant achieves a poorer outcome than they would have if everybody had chosen otherwise (i.e., to cooperate). Although cooperation is advantageous for both parties, economic theory is clear that every rational agent will defect in a one-shot prisoner's dilemma.

In this experiment, the defection rates of economics students were $60.4 \%$, compared with $38.8 \%$ for non-economics students. Economics students, as usual, get closer to the predictions of economic theory. Since, yet again, the differences are present even when comparing junior economics and non-economics students, there must be some selfselection at play. Frank and his colleagues, however, also show that the 
longer the participants had been trained in economics, the more they expected other people to be dishonest and therefore, probably, to defect. This fits together with the further observation that, whereas the progress of non-economics education is correlated with an increase in cooperative behaviour, the same pattern is not observed among economics students, suggesting that "the training in economics plays some causal role in the lower observed cooperation rates of economists" (Frank, et al. 1993, 168). This causal role, however, is not identified or explored elsewhere in the literature.

Before assessing the merits of the self-selection explanation, however, let me turn to some remarks on the kind of evidence offered by these experiments.

\section{SOME METHODOLOGICAL OBSERVATIONS}

In reaction to the moral accusations lingering around this experimental evidence, many scholars began producing counterevidence. For example, the results of several field experiments showed that more students of economics than students of other disciplines who found abandoned envelopes containing dollar bills, returned them to the owners instead of pocketing the cash (Yezer, et al. 1996); that at the University of Zurich more students of political economy than students of business administration, medicine, or veterinary science contributed to voluntary social funds to support needy students and foreigners (Frey and Meier 2003); and that more practicing economists than political scientists or sociologists declare their real income and pay their professional associations membership fees accordingly (Laband and Beil 1999). ${ }^{2}$

Besides handling these ambiguous results, an assessment of the moral trial has to come to terms with the problem of pinpointing vague concepts like 'selfishness' or even 'more selfish' than someone else. Most authors seem unconcerned with specifying the charge of selfishness in much detail. Frank and his co-authors $(1996,192)$ observe that in the debate with Yezer and his co-authors, and also more generally among the contributors to this literature, there are three points of agreement: "that economics training encourages the view that people are motivated primarily by self-interest", since many economists maintain that "the average human being is about 95 percent selfish in the narrow sense of the term" (Tullock 1976, quoted in Frank, et al.

\footnotetext{
${ }^{2}$ For a more complete review, see Kirchgaessner 2005. For more detailed scrutiny of the moral trial, see Lanteri 2008b.
} 
1993, 159). Moreover, "this view leads people to expect others to defect in social dilemmas" (Frank, et al. 1996, 192). Economics students' ratings of the likelihood that a businessman would honestly report a mistaken bill (to his disadvantage) dropped after one term of training in microeconomics (Frank, et al. 1993, 168ff.). The third point of agreement is that people who hold such expectations "are overwhelmingly likely to defect themselves" (Frank, et al. 1996, 192). Indeed, "almost all respondents (30 of 31 economics students and 36 of 41 non-economics students) said they would defect if they knew their partner would defect" (Frank, et al. 1993, 167). In other words, the economics students may behave selfishly because they anticipate dishonesty. So they may be protecting themselves, in a display of mild self-interest, or they may be animated by a sense of justice in punishing the dishonest co-player, and in such ways come to behave exactly as a selfish person would.

Another interpretation of uncooperative behaviour, different from self-interest, has also been proposed. Marwell and Ames (1981) label the small contributions in their public good experiment as distinctly economic conduct, and explain it by the observation that "the meaning of 'fairness' in this context was somewhat alien" to economics students, who were half as likely as non-economics students to say they were "concerned with fairness" and who believed that tiny or zero contributions were fair. They admit that such a difference may be associated with the self-selection of economists "by virtue of their preoccupation with the 'rational' allocation of money and goods", or be the result of their "behaving according to the general tenets of the theories they study" (Marwell and Ames 1981, 309), although they do not discriminate between these explanations. Uncooperative behaviour is thus seen as the outcome of a 'different understanding' of fairness, either pre-existing and associated with rationality or acquired through economics indoctrination.

Such interpretations notwithstanding, the subsequent articles simply took observations of uncooperative behaviour as evidence of selfishness. Though their study investigates cooperation in a prisoner's dilemma and though defection as they characterise it may be ascribed to self-defence or to a sense of justice, Frank and his colleagues (1993, 163) seem to ultimately regard their game as "a rich opportunity to examine self-interested behavior", and defection rates as a measure of self-interest. 
The literature also employs a variety of other criteria for measuring self-interest besides uncooperative behaviour. Anthony Yezer and his colleagues use the return rates of envelopes containing dollar bills as a measure of cooperation, but it has been convincingly argued that their field experiment elicits observations of (dis)honest behaviour rather than (non)cooperation (Zsolnai 2003). Both not cooperating and behaving dishonestly can be seen as manifestations of self-interested conduct, and so can the lower accepted and lower proposed offers of economics students compared with non-economics students in Carter and Irons's ultimatum game (Carter and Irons 1991).

These numerous possible indications of self-interested conduct, however, may blur rather than advance the result of the moral trial. For instance, David Laband and Richard Beil $(1999,86)$ describe economists as "honest/cooperative", though the two are distinct concepts, and refer to free-riding on professional associations' fees as "cheating", though admittedly cheating may not be "the appropriate description for the behavior that [they report]" (99n.). It is indeed remarkable that they concur in such oversimplifications, since they are aware that "the terms 'selfish', 'uncooperative', 'dishonest', and 'cheater' [...] are not perfect substitutes" (99n.). They nonetheless follow in the tradition of mixing these terms because they sense that there is a "general shared meaning", so that all the authors involved in the moral trial refer to "the same kind of behavior: selfish versus unselfish, cooperative versus uncooperative, etc." (99n.).

I doubt that this emphasis on these contrasts provides a clearer concept of self-interest; if anything, it complicates the definition because it suggests that not only does selfishness equal cheating and defection, but also that unselfishness equals honesty and cooperation. That these authors believe it to be clearer, however, makes the important point that, in order to make sense of the experiments, one needs to subscribe to two central conjectures. On the one hand, one must believe that a selfish subject defects in the prisoner's dilemma, makes and accepts small offers in the ultimatum game, free-rides in the provision of a public good, is dishonest when he finds an envelope full of money, and so on. On the other hand, one must also believe that someone who acts in these ways is selfish. Such actions are indeed compatible with selfishness, but it does not follow that they must always be exclusively motivated by selfishness. Though in theoretical research it may be both useful and plausible to assume self-interest as 
the sole motivation of human behaviour, the assumption is inadequate to address empirical questions about actual behaviour in a range of only slightly similar circumstances.

At any rate, for someone who accepts the two conjectures, experimental evidence gathered under the auspices of the standard economics assumption that individuals behave as homines economici may, depending on its interpretation, be used to address two types of questions. The empirical investigation of a descriptive theory examines whether the theory corresponds closely enough to observations, and so it tests whether the theory is accurate. On the other hand, the empirical testing of a normative theory can say nothing about its accuracy, since it can only investigate whether the observed behaviour fits with the standards set by the theory itself.

Therefore, if one considers standard economics as a descriptive account of individual behaviour, one may empirically test whether it is accurate, as Marwell and Ames (1981) did when they conducted their experiments precisely in order to prove that most subjects do not freeride as economic theory would have them. The other contributors to the moral trial literature, however, have nothing to say about the descriptive accuracy of economic theory. If one instead considers microeconomics as a normative theory of how an individual ought to behave in order to be rational, one could empirically investigate how many subjects fail at behaving as they ought to, and therefore behave irrationally. A comparison of the different degrees of irrationality prevailing among various groups of subjects with different educations might be an interesting academic pursuit, especially if understanding the differences helped with correcting the failures, so that more people behaved in line with rationality and thus with economic theory. God forbid!

As mentioned above, economics and economists are not very much liked. The critics blame economics because it has twisted evil into looking good in a way that is "intellectually acceptable" (Lux 1990, 135) so that immorality now finds its "intellectual and theoretical justification in the name of economics" (Lux 1990, 129), with the consequence that this 'dismal' discipline has really become "pernicious" (Moffat 1878, 5) and it should "be simply swept away" (Henderson 1981, 12). Though not all critics of economics are so severe, there seems to be a presumption that the closer to the standards set by microeconomics, the less ethically one behaves. The moral trial thus seems to take a 
peculiar twist in considering microeconomics as a normative theory of what an individual should not do in order to be moral. ${ }^{3}$

Laszlo Zsolnai (2002, 40-41) seems to endorse this moral-normative interpretation of the moral trial when he mentions these experiments as those "famous studies [showing] that people are moral beings in their economic actions", because they do not behave as economic theory predicts. It is the very same experiments that force Frank, et al. (1996) to respond to the allegations that 'economists make bad citizens', because they arguably $d o$ behave as economic theory predicts, and so on. These justified, but contradicting interpretations of the same experimental result amount to the problem of under-determination of theories by data (Quine 1951), a methodological problem according to which it is virtually impossible to find evidence which demonstrates that a theory is correct. Instead, the most we can strive for would be evidence that could disprove an interpretation, following Karl Popper's (1969) falsificationism, according to which scientists should begin with a theory or a conjecture and then conduct experiments that could show the starting theories and conjectures wrong. A theory is then provisionally upheld, insofar as it is not falsified (although even falsifying a theory may not be straightforward). ${ }^{4}$

If the starting assumption is that economists behave the way economic theory predicts, however, we must acknowledge that "even economists sometimes fall short of the behaviour expected of all good homines economici" (Carter and Irons 1991, 177). For instance, in their ultimatum game experiment, the average amount kept ( $\$ 6.15$ out of $\$ 10)$ is fifteen standard deviations from the prediction of economic theory (\$9.99) and $40 \%$ of the economics students offer the 50-50 division. In the standard prisoner's dilemma, $40 \%$ of the economics majors cooperate and, when they are allowed to make a promise to cooperate, the figure rises to $71.4 \%$ (non-majors: $74.1 \%$ ), although economic theory considers such unenforceable promises irrelevant and dismisses them as 'cheap talk'.

Given that about half of the sample in Carter and Irons's experiment behaves in plain contradiction with economic theory's 'canons of immorality' and that many subjects deviate from its predictions, if one

\footnotetext{
${ }^{3}$ I shall on this occasion overlook the numerous problems that arise when equatingas mentioned above-certain observed behaviours with selfishness, selfishness with immorality, and then those behaviours with immorality.

${ }^{4}$ This methodological orientation was rather common among the early experimental economists (e.g., Smith 1982), however, it was later abandoned (Santos 2006, ch. 6).
} 
hypothesised that this is how they behave the evidence of the moral trial should be perhaps best interpreted as falsifying the hypothesis. It would follow that the assumption that individuals-and specifically economists-are immoral like a homo economicus should be abandoned. Of course, what matters in the moral trial are not the absolute levels, but the differentials between economists and non-economists. The real origin of these differentials, however, is seldom explored and most authors account for their evidence by essentially suggesting that, unlike the rest, economics students are homines economici who self-select in the discipline.

\section{SELF-SELECTION}

Although the methodological weaknesses of the moral trial experiments just reviewed already cast some legitimate doubts over the charge that economists are selfish, there are also other specific problems concerning the prescriptions for changing the teaching of economics.

Teaching economics students that non-selfish motivations may play a major role in the conduct of economic transactions (as suggested by Frank, et al. 1996) would not work. Employing less mathematics and more case studies in economics classes (as suggested by Rubinstein 2006) would make no difference. Why? Because self-selection blames the observed differences in behaviour on differences that existed before the students were indoctrinated. The differences are not brought about by economists teaching formal models of rational self-interested choice, so there is no need for change. This conclusion overlooks the possibility that, while standard economics classes may not stimulate selfish behaviour, different teaching methods may mitigate it and so override the original differences and 'correct' economics students into less selfish people. For example, Harvey James and Jeffrey Cohen (2004) showed that students who attended an ethics module had higher rates of cooperation in a prisoner's dilemma experiment than those who did not attend. Yet, one might retort, selfish people would never enrol in such courses.

The alleged ineffectiveness of the proposed solutions, however, invites closer scrutiny of the standing of the self-selection explanation and its exact meaning. It was Marwell and Ames (1981) who first suggested the two most obvious accounts for the observed behavioural differences between economics and non-economics students: learning, which refers to the outcome of economics training, and selection, which 
refers to a pre-existing individual inclination. As noted above, the observation that the behavioural differences are already present between freshmen, is seen by most authors as sufficient ground to dismiss the training hypothesis and, ipso facto, "support the selection hypothesis" (Frey and Meier, 2003, 452), without allowing for any alternative explanation. Their evidence does challenge the learning hypothesis, but it achieves very little in the way of corroborating selfselection, which is but one of many possible alternatives.

The concept of self-selection itself is far from clearly spelled out. In the experimental literature, self-selection refers to the morally neutral problem that individuals with certain characteristics are especially likely to belong to certain groups, so that these groups are not truly representative of the population at large and therefore constitute a poor sample. As a consequence, the results obtained from such groups are not externally valid, which means that they cannot be extended to the entire population. In the moral trial, the target characteristics are not morally neutral: Carter and Irons $(1991,175)$ run regressions that substantiate the conclusion that economics majors differ from others not because "they are more skilled at the sort of deductive logic required to recognize and determine opportunities for economic gain", but rather differ "in terms of sentiments". Roughly speaking, the idea is that economics students display uncooperative conduct because "selfish persons choose to study economics" (Frey and Meier, 2003, 448), so that they must also have been selfish individuals before enrolling in economics. None of the experiments, however, attempts to track such inclinations to high school students, which might corroborate the hypothesis.

In the moral trial, self-selection is regarded not as a methodological shortcoming to avoid, but as a phenomenon to exploit. The comparison between the group of economics students and the group of noneconomics ones is aimed precisely at 'measuring' the separation between the two groups. Yet these experiments do not attempt to show that economists differ from the general population, thus interpreting self-selection as above, but to show that they differ from specific subgroups. This attempt, however, appears to overlook a logical fallacy: that someone is not like everyone else does not entail that he is different from everyone else.

Perhaps if we had a truly complete pool of subjects-ideally comprising everyone-we would find that they collectively behave just 
like economists, because those who are more selfish and those who are less selfish than economists average out, so that economists turn out to be a representative sample after all. In the moral trial experiments (with the exception of Frey and Meier's, and Laband and Beil's), the conduct of economics students is nonetheless contrasted with that of very heterogeneous groups of non-economists that are far from being complete. This comparison seems to rest on the quite unlikely simplifications that non-economists are all alike, and that they are all different from economists in roughly the same way. It therefore seems that what should be an hypothesis to test-namely, that economists are different from the population at large-already constitutes a tacit assumption embedded in the setup of these experiments, and a tacit assumption of the kind that causes the methodological problem of theory-ladenness, that a scientist's prior theoretical assumptions affect the observations she elicits (Kuhn 1962). This also clarifies why Frank et al. (1996) complain against Yezer et al. (1996) that the students of biology used as a control group are trained with principles of natural selection founded on self-regarding behaviour that do not distinguish them sufficiently from economics students. They also complain against Marwell and Ames (1981) that the graduate students of economics they target and the high school students they use as a control group differ in several respects and therefore the observed differences in conduct may be caused by other factors, such as gender and age. Beside age and gender, there are other individual factors that remain overlooked in these experiments and the behavioural differences are accounted for only by means of a selective comparison between educational choices.

Given the virtual impossibility of conducting experiments on a complete pool of subjects, a more convincing case could hinge on the proof that economics students have some selfish personality trait, which explains why they behave selfishly, and that this trait is at work across all situations. Such a generalization, however, is contradicted by several findings from social psychology research, in which it is shown that situational factors affect individual behaviour to such a major extent (Darley and Batson 1973; Milgram 1974) that it is implausible that individuals consistently behave in accordance with some fixed personality. For instance, in one famous study (Milgram 1974), 65\% of the participants actively murder an associate of the experimenters after he fails to answer some simple questions. Whereas the death was staged, the killing felt real. This dramatic observation, however, is not 
usually interpreted as meaning that the majority of Americans have a murderous personality, but that-under the rule of certain institutions, in some circumstances-even ordinary people may be pushed to behave in ways that are totally alien to their nature, that even a great evil may ultimately be caused not by the utmost cruelty, but more banally by following to the extreme the rules of one's institutions and situation (e.g., Arendt 1963).

The upshot of these findings is usually that "there is no empirical basis for the existence of character traits" (Harman 1999, 316) and this suggests that they can still be instrumentally employed as a tool for explanatory or predictive purposes (in other words, people behave 'as if' they possess certain character traits) or that they should be eliminated from theory as a misguided illusion. Regardless of how one defines the trait of selfishness, neither of these suggestions would seem to sustain a moral charge against economists. It also seems that the allegations about the type of character traits, with which nature endowed economists and which guide them to Econ-101, should be softened.

On the other hand, it may be conceded (Miller 2003, 381ff.) that there exist 'local character traits', which are activated in connection with narrowly defined situations of a certain kind. Someone may be a cheater when it comes to certain school tests but not a cheater all-around (Hartshorne and May 1928), or he could be talkative at lunch, but not on other social occasions (Newcomb 1929). Admittedly, narrowly defined situations that are different along a variety of dimensions may nonetheless elicit the same character trait. Therefore, one may simply show that the conditions encountered in the moral trial experiments are largely similar, if not to all, then to some everyday situations that elicit the trait of selfishness, so that economists' conduct can be generalised to a broader pattern. Alternatively, a narrower, but sufficient and more meaningful, ground for the case at hand would be to argue that the game theoretical experimental setups reproduce the central features of the decision to enrol in economics or in other majors.

This condition is reminiscent of the classical interpretation of game theory, according to which games capture the physical and institutional features of real world situations. In practice, however, this is not what happens (Janssen 1998): a game is not a full description of the elements of a situation, but rather a "description of the relevant factors involved in a specific situation as perceived by the players" (Rubinstein 1991, 917). 
In the very moment that a game is embedded in a lab, however, it becomes very hard to predict what factors will become salient to each individual player. Norms of fairness, competitiveness, reputation effects, curiosity, intrinsic motivation, and the like, all seem to play a role together with or beyond the nominal payoff, and to do so in a highly idiosyncratic manner. Outside of the lab, in the complex real world, these matters become yet more difficult to capture, so that a direct connection between degree and career choices and conduct in the experiments may be very hard to establish.

The charge that economists are more selfish seems to rest on another tacit assumption: that the choice of different majors is associated with individual differences of some kind and thatconversely-the choice of the same major reflects some personal affinity. Christopher Boone, Woody van Olffen, and Nadine Roijakkers (2004) propose evidence supporting this intuition: different personalities are associated with various degrees of rationality in the choice process of selecting a major, and with the final choice itself. ${ }^{5}$ This very evidence, however, also poses a challenge because the four different disciplines included in this study were economics, business administration, business education, and international economics and business studies. If large differences are present among the students who study these disciplines, which on the surface seem to be quite similar, then perhaps there exist even larger differences between them and students in disciplines such as chemistry and fine arts, although such evidence has not yet been produced.

At any rate, choosing a major is but the first step in one's professional life. At a later stage, young graduates must also make a choice between either continuing studying or entering a job, and then among several career opportunities. For example, less than 50\% of economics majors continue their education beyond the bachelor, and only about $3 \%$ pursue an advanced degree in the same field, while those who do not become non-economists. Therefore, very few graduates call themselves "economists" when they enter a job (Siegfried, et al. 1991,

\footnotetext{
${ }^{5}$ Following Julian Rotter's studies on personality $(1954,1966)$, in which students were classified either as having an internal locus of control (i.e., they had confidence in their capacity of affecting the events in their lives) or an external locus (i.e., they considered the events in their lives as driven mainly by forces beyond their control, such as chance or other people). Those with an internal locus were later found to be more likely to have actively searched for information prior to enrolment, and to have chosen study programs leading to more uncertain professional environments (e.g., international business, as opposed to teaching economics).
} 
198). The U. S. Bureau of Labor (2007) estimates that there are 13,000 practitioners of economics presently active in the U. S. (a surprisingly small figure for a country in which over 30,000 students major in the field every year). These economists are variously employed in public administration, in politics, in international organizations, in public and private research institutes, in different types of teaching engagements, in consulting firms, in the media (Coats 1981, 1986, 1989; Frey 2000; Mandel 1999), though most economists still consider academia their career of choice (Scott and Siegfried 2002), where they are joined by the many $\mathrm{PhDs}$ in economics and econometrics, who originally followed bachelors in 'non-economics' (45\% of the total).

The self-selection/training dichotomy, therefore, not only unduly rules out other plausible explanations for the observed behavioural differences between economics majors and non-majors (more on this below), but it also overlooks the heterogeneity of both training and selfselection: high school students self-select into economics majors, are thus trained in economics, later some of them self-select into graduate students and are again trained, and then all self-select into a variety of professions.

At each stage, some (and different) self-selection and learning take place. Neither economics and non-economics students, nor economists proper and non-economists, are tightly isolated and many students who are made into economists at some stage are, so to speak, unmade at a later stage and vice versa. Nonetheless, economics doctoral students contribute more to the University of Zurich social funds than doctoral students of other disciplines, despite the fact that these are the people who have both "absorbed the largest amount of economics teaching" (Frey and Meier 2005, 168) and self-selected the most times. And this observation questions, once again, the charge of selfishness that has been levied against economists.

\section{CONCLUDING REMARKS}

Are economists different? Probably. There exist numerous surveys, like the sources I briefly mentioned in the introduction, which expose the differences in moral and political opinions between economists and non-economists. I also reviewed many experimental observations that economists behave differently from non-economists in a stream of literature that puts economists on trial on allegations of selfishness, although it is not always easy to identify precisely either the charge of 
selfishness or who are the indicted in this moral trial. Such differences can be tracked to two possible and related problems: economists fail at distancing themselves from a normative standard to be avoided and/or economists do not regard such a normative standard as a standard to be avoided. The first problem would seem to indicate that economists are to a large extent morally incompetent. Though such a question could certainly be investigated with existing and well-known tools (Kohlberg 1984; Lind 1987), I am not aware of any findings produced along this line of research. On the other hand, economics students may believe that the decision-context within which they behave selfishly is one in which self-interest is not necessarily blameworthy. Perhaps they are truly born selfish and therefore think all opportunities to earn a buck must be seized, or perhaps they have been indoctrinated to expect others to be unreliable egoists and therefore to be guarded against. Both explanations seem plausible and are probably true of some economists. Yet, there exist other possible accounts.

When a given situation is framed as a market, most people behave more selfishly (Liebermann, et al. 2004), because there is broad acceptance of self-interest in market-like contexts or it may even constitute the social norm to follow (Bicchieri 2006). A candidate explanation for the evidence presented above would thus be that economics students frame decision-contexts differently from students of other disciplines, and specifically in a way that is more in line with the subject they study. Undergraduate economics classes put a strong emphasis on the so-called 'economic way of thinking', according to which each decision is best seen as a trade-off and each choice as a price to pay. It would therefore not be surprising if economics majors framed decision-contexts as markets more often than non-majors, and therefore also behaved selfishly more often, while believing they were simply doing the normal thing for the occasion at hand (Lanteri 2008a).

A related interpretation would be that the application of economic theory in the experiments reflects economics students' perception of the lab tasks as "an IQ test of sorts" (Frank, 1988, 226), in which they ought to apply the theories they had been taught. Such accounts could explain the observed behavioural differences between students of economics and non-economics, but they presume the acquisition of (at least some) economics knowledge.

The training explanation, after all, should not be too easily dismissed. The "logical implications" of Frank and colleagues' three 
points $(1996,192)$-economics promotes cynical views of other people, such views support anticipations of defection from other people, such anticipations encourage defection-"place a heavy burden on those who insist that economics training does not inhibit cooperation". Showing that a difference in behaviour between economics majors and nonmajors already existed is not enough to prove that training is irrelevant. After economics training, the observed behavioural differences remain, but they may be caused by different motives. Uncooperative behaviour may be the result of self-interest, but also compliance with social norms, a sense of justice, a lack of concern with fairness, and so on. Perhaps, economics seniors defect in the prisoner's dilemma because they had learned that framing, which they had not known when they were freshmen, and yet they also defected as freshmen, but for a different reason. The lab, field, and natural experiments employed in the literature so far are unfit to discriminate among different motivations for a targeted behaviour. Admittedly, when learning has not yet been possible but the difference can already be observed, as during the early weeks of college, the framing explanation I sketched becomes insufficient. Another plausible account of the early differences, however, can be proposed to side with framing.

Individuals behave in consonance with their identity, which is largely shaped by their current role and by the social expectations that role carries. It seems plausible that freshmen play the way they believe an economist should behave. Such a belief, moreover, probably follows some stereotypical idea of economists. Do such stereotypes exist, and what are they like? These stereotypes do exist, also outside of economics, and they are not very flattering. For example, unless they are given special instructions, students of occupational therapy do not defect very much in a prisoner's dilemma experiment. When they play with a student of economics or when they are asked to play 'as if' they were students of economics, however, they immediately start defecting and they do so slightly more than actual economics students (Lanteri and Rizzello 2008). If there were no stereotype of an economist, the students should be puzzled by the instructions, but they are not. They adjust both their decisions and their expectations very quickly. On the other hand, this evidence may hint that students of occupational therapy are not intrinsically less selfish or more moral because they do not defect: it is enough to let them see the situation under a different perspective to critically alter their responses. In other words, there is no 
need to posit a difference in character dispositions between economics and non-economics majors, but simply examine the combination of the individual's perceptions of her circumstances with her self-image. This way we do not necessarily reject self-selection, but we make our explanations less dependent on it.

Since its inception, the contributors to the moral trial literature have been concerned with discriminating between but two possible explanations: the self-selection of selfish individuals, and the indoctrination of cynical expectations or rational choice. There is, however, no need to stick to this dichotomy or to only one side of it. From high school onwards, there are a plurality of explanations that may capture the observed differences in behaviour between economists and non-economists: some economists may be selfish and self-select into the discipline; upon joining its ranks, some may adjust their decisions to those of the stereotypical economist; systematic exposure to the concepts of self-interest and trade-offs may make those concepts especially salient and therefore more likely to characterise one's framing of a situation; and, over time, the repeated exposure to the focus on material individual incentives may induce the expectation that other people are greedy or the belief that fairness need not be a major concern. These explanations are not mutually exclusive and it may very well be the case that different explanations are appropriate for the behaviour observed in different experimental tasks and for economists of different seniority.

In spite of the broad support for the self-selection explanation, any good description of what it amounts to or of the ways in which it plays out is regrettably lacking. My contention is that there remains ample room for further inquiries. The outcome of such inquiries will hopefully clarify whether the moral trial stands, and so also whether corrections are necessary and possible.

\section{REFERENCES}

Arendt, Hanna. 1963. Eichmann in Jerusalem: a report on the banality of evil. New York: Viking Press.

Bicchieri, Cristina. 2006. The grammar of society: the nature and dynamics of social norms. Cambridge: Cambridge University Press.

Boone Christopher, Woody van Olffen, and Nadine Roijakkers. 2002. Locus of control and study program choice: evidence of personality sorting in educational choice. Research Memoranda 005, Maastricht: METEOR. 
Caplan, Bruce. 2001. What makes people think like economists? Evidence on economic cognition from the survey of Americans and economists on the economy. Journal of Law and Economics, 44 (2): 395-426.

Carter, John, and Michael Irons. 1991. Are economists different, and if so, why? Journal of Economic Perspectives, 5 (2): 171-177.

Coats, Alfred. 1981. Economists in government: an international comparative study. Durham (NC): Duke University Press.

Coats, Alfred. 1986. Economists in international agencies: an exploratory study. New York: Praeger.

Coats, Alfred. 1989. Economic ideas and economists in government: accomplishments and frustrations. In The spread of economic ideas, eds. David Colander, and Alfred Coats. Cambridge: Cambridge University Press, 109-118.

Colander, David. 2007. The stories economists tell: essays on the art of teaching economics. New York: McGraw-Hill.

Coleman, William. 2004 [2002]. Economics and its enemies: two centuries of antieconomics. New York: Palgrave MacMillan.

Darley, John, and Daniel Batson. 1973. 'From Jerusalem to Jericho': a study of situational and dispositional variables in helping behaviour. Journal of Personality and Social Psychology, 27 (1): 100-108.

Ehrenberg, Ronald. 1999. The changing distribution of new Ph.D. economists and their employment: implications for the future. Journal of Economic Perspectives, 13 (3): 135-138.

Frank, Bjorn, and Gunther Schulze. 1998. How tempting is corruption? More bad news about economists. Diskussionsbeiträge aus dem Institut für Volkswirtschaftslehre, Universität Hohenheim, 164/98.

Frank, Robert. 1988. Passions within Reason. New York: Norton.

Frank, Robert, Thomas Gilovich, and Dennis Regan. 1993. Does studying economics inhibit cooperation? Journal of Economic Perspectives, 7 (2): 159-171.

Frank, Robert, Thomas Gilovich, and Dennis Regan. 1996. Do economists make bad citizens? Journal of Economic Perspectives, 10 (1): 187-192.

Frey, Bruno. 2000. Does economics have an effect? Towards an economics of economics. Wirtschaftspolitik, 1 (1): S. 5-33.

Frey, Bruno, and Stephen Meier. 2005. Selfish and indoctrinated economists? European Journal of Law and Economics, 19 (2): 165-171.

Frey, Bruno, and Stephen Meier. 2000. Political economists are neither selfish nor indoctrinated. IEW-Working Paper, No. 69. Institute for Empirical Research in Economics (IEW), Zurich.

Frey, Bruno, and Stephen Meier. 2003. Are political economists selfish and indoctrinated? Evidence from a natural experiment. Economic Inquiry, 41(3): 448462.

Frey, Bruno, Werner Pommerehne, and Beat Gygi. 1993. Economics indoctrination or selection? Some empirical results. Journal of Economic Education, 24 (3): 271-281.

Fuller, Dan, and Doris Geide-Stevenson. 2007. Consensus on economic issues: a survey of republicans, democrats, and economists. Eastern Economic Journal, 33 (1): 8194.

Harman, Gilbert. 1999. Moral philosophy meets social psychology: virtue ethics and the fundamental attribution error. Proceedings of the Aristotelian Society, 99: 315-331. 
Hartshorne, H., and M. May. 1928. Studies in the nature of character: I. studies in deceit. New York: Macmillan.

Haucap, Justus, and Tobias Just. 2003. Not guilty? Another look at the nature and nurture of economics students. University of the Federal Armed Forces Economics Working Paper, No. 8. Hamburg.

Henderson, Hazel. 1981. The politics of the solar age: alternatives to economics. New York: Anchor Press.

Hu, Yung-An, and Day-Yang Liu. 2003. Altruism versus egoism in human behaviour of mixed motives. American Journal of Economics and Sociology, 62 (4): 677-705.

James, Harvey, and Jeffrey Cohen. 2004. Does ethics training neutralize the incentives of prisoner's dilemma? Journal of Business Ethics, 50 (1): 53-61.

Janssen, Marten. 1998. Individualism and equilibrium coordination games. In Economics methodology: crossing boundaries. Proceedings of the IEA conference, eds. R. Backhouse, D. Hausman, U. Mäki, and A. Salanti. London: MacMillan, 1-35.

Kearl, J. R., Clayne Pope, Gordon Whiting, and Larry Wimmer. 1979. A confusion of economists? American Economic Review, 69 (2): 28-37.

Kirchgaessner, Gebhard. 2005. (Why) are economists different? European Journal of Political Economy, 21 (3): 543-562.

Klamer, Arjo. 2007. Speaking of economics: how to get in the conversation. London: Routledge.

Kohlberg, Lawrence. 1984. The psychology of moral development. San Francisco: Harper and Row.

Kuhn, Thomas S. 1962. The structure of scientific revolutions. Chicago: University of Chicago Press.

Laband, David, and Richard Beil. 1999. Are economists more selfish than other 'social' scientists? Public Choice, 100 (1-2): 85-101.

Lanteri, Alessandro. 2008a. The moral trial: on ethics and economics. Doctoral Dissertation. Rotterdam: Erasmus Universiteit Rotterdam.

Lanteri, Alessandro. 2008b. Guilty until proven innocent: economists and the moral trial. mimeo.

Lanteri, Alessandro, and Salvatore Rizzello. 2008. Ought (only) economists to defect? Stereotypes, identity, and the prisoner's dilemma. Quaderni SEMeQ 21/07.

Liberman, Varda, Steven Samuels, and Lee Ross. 2004. The name of the game: predictive power of reputations versus situational labels in determining prisoner's dilemma game moves. Personality and Social Psychology Bulletin, 30 (9): 11751185.

Lind, G. 1987. Moral competence and education in democratic society. In Conscience: an interdisciplinary approach, eds. G. Zecha, and P. Weingartner. Dordrecht: Reidel, 91-122.

Lux, Kenneth. 1990. Adam Smith's mistake: how a moral philosopher invented economics and ended morality. Boston: Shambhala Publications.

Mandel, Michael. 1999. Going for the gold: economists as expert witnesses. Journal of Economic Perspectives, 13 (2): 113-120.

Marwell, Gerald, and Ruth Ames. 1981. Economists free ride, does anyone else? Experiments on the provision of public goods, IV. Journal of Public Economics, 15 (3): 295-310. 
McCloskey, Deirdre. 1990. If you're so smart: the narrative of economics expertise. Chicago: University of Chicago Press.

Milgram, Stanley. 1974. Obedience to authority. San Francisco: Harper \& Row.

Miller, Christian. 2003. Social psychology and virtue ethics. The Journal of Ethics, 7 (4): 365-392.

Moffat, Robert. 1878. The economy of consumption: an omitted chapter in political economy. London: Kegan Paul.

Newcomb, Theodore M. 1929. The consistency of certain extrovert-introvert behavior patterns in 51 problem boys. New York: Columbia University College Bureau of Publications.

Popper, Karl R. 1969 [1963]. Conjectures and Refutations. London: Routledge \& Kegan Paul.

Quine, Willard V. O. 1951. Two dogmas of empiricism. Philosophical Review, 60 (1): 2043.

Rhoads, Steven. 1985. The economist's view of the world: government, markets and public policy. Cambridge: Cambridge University Press.

Rotter, Julian. 1954. Social learning and clinical psychology. Englewood Cliffs (NJ): Prentice Hall.

Rotter, Julian. 1966. General expectancies for internal versus external control of reinforcement. Psychological Monographs, 80 (609): 1-28.

Rubin, Paul. 2003. Folk economics. Southern Economics Journal, 70 (1): 157-171.

Rubinstein, Ariel. 1991. Comments on the interpretation of game theory. Econometrica, 59 (4): 909-924.

Rubinstein, Ariel. 2006. A sceptic's comment on studying economics. Economic Journal, 116: c1-c9.

Santos, Ana. 2006. The social epistemology of experimental economics. Doctoral Dissertation. Rotterdam: Erasmus Universiteit Rotterdam.

Scott, Charles, and John Siegfried. 2007. American association universal academic questionnaire summary statistics. American Economic Review, Papers and Proceedings, 97 (2): 588-591.

Siegfried, John, Robin Bartlett, Lee Hansen, Allen Kelley, Donald McCloskey, and Thomas Tietenberg. 1991. The status and prospect of the economics major. Journal of Economic Education, 22 (3): 197-224.

Siegfried, John, and Wendy Stock. 1999. The labor market for new Ph.D. economists. Journal of Economic Perspectives, 13 (3): 115-134.

Smith, Vernon. 1976. Experimental economics: induced value theory. American Economic Review, 66 (2): 274-279.

Smith, Vernon. 1982. Microeconomic systems as an experimental science. American Economic Review, 72 (5): 923-925.

Stigler, George J. 1959. The politics of political economists. Quarterly Journal of Economics, 73 (4): 522-532.

U. S. Bureau of Labor Statistics. 2007. Economists. Occupational Outlook Handbook, 2006/2007 Edition, at the United States Department of Labor Website. www.bls.gov/oco/ocos055.htm (accessed July 2007).

Yezer, Anthony, Robert Goldfarb, and Paul Poppen. 1996. Does studying economics discourage cooperation? Watch what we do, not what we say or how we play. Journal of Economic Perspectives, 10 (1): 177-186. 
Zsolnai, Laszlo. 2002. The moral economic man. In Ethics in the economy: handbook of business ethics, eds. Laszlo Zsolnai. Bern: Peter Lang Academic Publishers.

Zsolnai, Laszlo. 2003. Honesty versus cooperation. American Journal of Economics and Sociology, 62 (4): 707-712.

Alessandro Lanteri is a post-doctoral fellow at the Department of public policy and public choice (POLIS), Faculty of political science, University of Piemonte Orientale (Alessandria, Italy). He holds a MA in economics, from Bocconi University (Milan, Italy); and an MPhil and a $\mathrm{PhD}$ in philosophy and economics, from EIPE at Erasmus Universiteit Rotterdam (The Netherlands). His main research interests rest at the meeting points between economics, moral philosophy, and psychology.

Contact e-mail: <alessandro.lanteri@sp.unipmn.it> 